\title{
Diagnoses of alcohol abuse and other neuropsychiatric disorders among house painters compared with house carpenters
}

\author{
Ingvar Lundberg, Annika Gustavsson, Magareta Högberg, Gun Nise
}

\begin{abstract}
The incidence of alcoholism and the incidence of other neuropsychiatric diagnoses were compared between the 767 house painters and the 1212 house carpenters, born in 1925 or later, who were members of the Stockholm branches of their respective trade unions in 1965 and who had been members for at least 10 years before 1970. Four different outcome registers were used: (1) the alcohol crime register, which contained all persons who had broken any law regulating the handling and consumption of alcohol (follow up period 1972-6). (2) The register of diagnoses at early retirement (follow up period 1971-84). (3) The register of diagnoses at discharge from inpatient psychiatric care (follow up period 1968-83). (4) The register of causes of death (follow up period 1965-86). Exposures to solvents and consumption of alcohol were evaluated by interviews with samples of the cohorts. A high average cumulative exposure to solvents was found among the painters. The mean consumption of alcohol was similar in the two cohorts. The incidence of diagnoses of neuropsychiatric disorders was higher in painters than in carpenters in all registers. Alcoholism was the most common neuropsychiatric disorder diagnosed and showed the highest relative risk. The excess of alcoholism among the painters was, however, due singularly to painters who had several registrations in the alcohol crime register or diagnoses of alcoholism in multiple registers. Thus the study implies that excessive alcohol consumption or severe damage due to alcohol, or both, but not less severe problems, were more common in painters than in carpenters. This suggests an interaction between
\end{abstract}

Department of Occupational Health, Karolinska Hospital, Stockholm, Sweden

I Lundberg, G Nise

Department of Occupational Medicine, National

Institute of Occupational Health, Solna, Sweden

A Gustavsson, $M$ Högberg exposure to solvents and intake of alcohol causing an increase in diagnoses of alcoholism among painters.

For many years it has been suspected that exposure to organic solvents may cause a brain dysfunction characterised mainly by impaired memory and concentration and affective changes. ${ }^{12}$ This syndrome could not immediately be summarised into a single diagnostic entity that could serve as the outcome in longitudinal epidemiological studies. Instead the outcome in such studies has usually been diagnoses of different combinations of neuropsychiatric disorders intended to cover the symptomatology allegedly elicited by exposure to solvents.

An excess of disability pensions due to such sets of neuropsychiatric disorders has been found among solvent exposed workers in several studies performed in the Nordic countries. ${ }^{3-7}$ A recent paper from the United States has verified the association. ${ }^{8}$ Studies from Switzerland and Holland have found excesses of some neuropsychiatric disorders, but not others, and the authors have been reluctant to attribute the findings to exposure to solvents. ${ }^{9-11}$ Another study from Great Britain could not verify the excess, ${ }^{12}$ but this study used diagnoses of psychiatric disorders obtained from sources other than a disability pension register as the outcome.

Some studies have considered the relation between solvent exposure and more serious conditionsnamely, presenile or senile dementia or related conditions. A case-control study performed among men admitted to a geriatric ward found an increased (but not statistically significant) relative risk (RR) for a set of diagnoses, mainly senile or presenile dementia and ischaemic cerebral atherosclerosis, among workers previously exposed to solvents. ${ }^{13}$ A casereferent study performed among men admitted to a psychiatric hospital showed an increased risk for various types of dementia among workers exposed to solvents. In this study exposure to solvents entailed a particularly high risk for dementia associated with alcoholism. ${ }^{14}$ Two case-referent studies on Alzheimer's disease and presenile dementia did not find 
increased RRs among workers previously exposed to solvents. ${ }^{15} 16$

In the Nordic countries it is now recognised that long term high exposure to organic solvents may lead to a chronic toxic encephalopathy, although this relation is not fully accepted in most other countries.

The Scandinavian studies have been criticised for confounding exposure to solvents with occupation, so that neuropsychiatric disease in solvent exposed occupations was regarded as immediately elicited by the exposure. ${ }^{17-18}$ An alternative explanation could be higher alcohol consumption in the exposed groups as this may result in the same clinical syndrome and the same disability. In fact, several of the studies have found an excess of diagnoses of alcoholism, particularly in house painters who have generally formed the main group of workers within the solvent exposed category in the different studies. ${ }^{389}$ A Swedish cohort study of the mortality pattern among painters showed excess mortality from alcoholism. ${ }^{19}$

The interpretation of the finding of excess alcoholism among painters has varied. One explanation has been that the diagnoses of alcoholism are misdiagnoses of the solvent syndrome. ${ }^{3}$ Another suggestion has been that painters drink more alcohol than workers in allied trades due to social and cultural differences. ${ }^{9}$ The possibility also exists that occupational exposure could induce an addiction to the effects of the solvents on the central nervous system similar to alcohol addiction. ${ }^{1}$ This might, in turn, lead to an increased consumption of alcohol. A final possibility may be that alcohol and solvents have additive, or synergistic, effects on the central nervous system. This would probably result in more diagnoses of alcoholism as well as other neuropsychiatric disorders in solvent exposed groups.

This study was designed to examine whether diagnoses of alcoholism are more common in house painters than in another group of construction workers-namely, house carpenters. Cohorts of painters and carpenters were followed up in four different outcome registers for diagnoses of alcoholism as well as diagnoses of other neuropsychiatric disorders.

\section{Material and methods \\ STUDY GROUP}

The study population consisted of all members in the painters' union and all carpenters in the union of building workers in Stockholm who were born during 1925 or later, who were members of the Stockholm branches of their respective trade unions in 1965, and who had been members for at least 10 years before 1970 . These painters had been working during the 1950s and 1960s when exposure to organic solvents was very high in Stockholm. ${ }^{20}$

Information on the eligibility criteria was collected from the membership registries of the respective trade unions. A total of 767 painters and 1212 carpenters met the inclusion criteria. Table 1 shows the distribution of person-years when the cohorts were followed up from the start of 1965 to the end of 1986. The painters were slightly younger than the carpenters with $48 \%$ of the person-years in the age groups below 40 compared with $43 \%$ among the carpenters.

\section{SOLVENT EXPOSURE AND ALCOHOL CONSUMPTION IN A} SAMPLE OF THE POPULATION

A sample of 148 painters and 85 carpenters was invited to a clinical examination in 1988-9 as part of a larger ongoing study. These workers were selected from the cohort members who had accessible psychometric tests (around $80 \%$ of both cohorts) performed in certain years at conscription $(1949,1951$, 1953, 1957, and 1961), and who were presently living in the Stockholm area. They were informed that the study concerned the relation between solvent exposure and health. Finally, 135 painters and 71 carpenters came to the examination. The mean years of birth among the painters and carpenters in the sample were 1936 and 1937, compared with 1936 and 1935 respectively in the entire cohorts.

The exposure of the men in the sample to solvents was evaluated in an extensive interview with an industrial hygienist. The cumulative exposure to organic solvents during their working life was, as expected, very high among the painters and low among the carpenters. A detailed account of the exposure evaluation will be published elsewhere.

The same sample of painters and carpenters was also interviewed by a physician about their average alcohol consumption each week during the past year. At the same time a blood sample was taken and analysed for $\gamma$-glutamyl transpeptidase (GGT) activity, an established indicator of alcohol induced liver damage. ${ }^{21}$ The mean stated alcohol consumption as well as the GGT activities were similar in the

Table 1 Distribution of person-years in five year age strata among the painters and carpenters with follow up during the period 1965-86

\begin{tabular}{lcccr}
\hline $\begin{array}{l}\text { Age } \\
(y)\end{array}$ & $\begin{array}{l}\text { Painters } \\
\text { Person-years }\end{array}$ & $(\%)$ & $\begin{array}{l}\text { Carpenters } \\
\text { Person-years }\end{array}$ & $(\%)$ \\
\hline $20-24$ & 7 & $(0 \cdot 1)$ & 1 & $(0 \cdot 0)$ \\
$25-29$ & 1139 & $(7 \cdot 6)$ & 1379 & $(5 \cdot 9)$ \\
$30-34$ & 2589 & $(17 \cdot 3)$ & 3584 & $(15 \cdot 3)$ \\
$35-39$ & 3402 & $(22 \cdot 7)$ & 5121 & $(21 \cdot 8)$ \\
$40-44$ & 3481 & $(23 \cdot 3)$ & 5641 & $(24 \cdot 0)$ \\
$45-49$ & 2433 & $(16 \cdot 3)$ & 4197 & $(17 \cdot 9)$ \\
$50-54$ & 1381 & $(9 \cdot 2)$ & 2371 & $(10 \cdot 1)$ \\
$55-59$ & 481 & $(3 \cdot 2)$ & 1060 & $(4 \cdot 5)$ \\
$60-64$ & 46 & $(0 \cdot 3)$ & 111 & $(0 \cdot 5)$ \\
Total & 14960 & $(100)$ & 23465 & $(100)$ \\
\hline
\end{tabular}

Calculation of person-years started on 1 January 1965 or 10 years after the entry into the union, whichever occurred latest, and ended at death or 31 December 1986, whichever occurred first (\% of the total number of person-years within each cohort). 
two groups. The painters consumed on average $93 \mathrm{~g}$ alcohol a week and the carpenters $89 \mathrm{~g}$. The mean GGT activity among the painters was $0.82 \mu \mathrm{kat} / 1$ and among the carpenters $0.84 \mu \mathrm{kat} / \mathrm{l}$. The median alcohol consumption was somewhat higher among the painters ( $71 \mathrm{~g}$ a week) than among the carpenters (56 g a week), but only $54 \%$ of the painters stated a consumption above the median among the carpenters. The participants were also asked whether they had previously consumed substantially more alcohol for any longer period; $16 \%$ of the painters $v 26 \%$ of the carpenters stated such consumption. Three of the interviewed painters $v$ five of the carpenters were registered due to diagnoses of alcohol abuse in one or more of the outcome registers described next.

\section{OUTCOMES}

The outcome was studied in the following registers.

(1) Register of diagnoses at early retirement ( $R D E R)$-This register contains all persons in Sweden that have received a pretime pension. All diagnoses on which the decision about early retirement was based were available, but only the first diagnoses were used in the comparisons between the painters and the carpenters. The register was followed up from the beginning of 1971 to the end of 1984. As the main outcomes in this register we used alcoholism (eighth revision of the International Classification of Diseases (ICD-8) 303; ICD-8 291, alcohol psychosis was also included, but there were no early retirements due to this diagnosis either among painters or among carpenters) and a set of socalled "relevant" diagnoses used by Axelson $e^{t} \mathrm{al}^{3}$ and Lindström et $\mathrm{Cl}^{4}$ with minor modifications to cover the neuropsychiatric effects caused by solvents. The diagnoses (ICD-8) were: 290 , senile and presenile dementia; 296-297 (excluding 296.1 and 296.3) depressive psychosis and paranoia; 300, neurosis; 301, pathological personality; 309.2 mental, nonpsychotic, disturbances due to cerebral lesion; 347, other diseases in the brain-for example, chronic toxic encephalopathy; 780.5 vertigo; 781.7 encephalopathy; 790 (excluding 790.19) nervousness; 791.99 headache.

(2) Register of diagnoses at discharge from inpatient psychiatric care $(R D P)$ - This register contains all diagnoses at discharge from inpatient psychiatric care. It was followed up from the beginning of 1968 to the end of 1983. All diagnoses were noted but only the first diagnosis at the first period of care was used in the comparisons between the two cohorts. The same main outcomes were used as in the RDER.

(3) Alcohol crime register ( $A C R$ )-All crimes linked to handling or consumption of alcohol were registered in Sweden between the 1920s and 31 December
1976. After this it was no longer illegal to appear drunk in public. Most of the registrations were caused by drunkenness in public. Driving while drunk was the second most common cause. The register was divided into a "current" part, which concerned the period from 1 January 1972 and a "historic" part, which concerned the time before this. When a person who had previously committed a crime committed a new crime in the period 1972-6 his file was transferred to the "current" register. We have investigated the current register and noted every registration among the cohort members.

(4) Register of causes of death (RCD)-The register was followed up from the start of 1965 to the end of 1986 and the primary cause of death was noted. The main outcomes used from this register were alcoholism (ICD-8 303 (no deaths occurred due to ICD-8 291, alcohol psychosis)), cirrhosis of the liver, and violent deaths as these causes are associated with excessive consumption of alcohol. It was also noted whether alcohol was mentioned on the death certificate as contributing to cause of death.

\section{STATISTICAL METHODS}

The outcomes were compared between painters and carpenters in the different registers. Age was stratified as five year categories for the comparison of the incidence of disease. The Mantel-Haenszel method was used to estimate the RR with its $95 \%$ confidence intervals $\left(95 \%\right.$ CIs). ${ }^{22}$ When the numbers of painters and carpenters in a particular category according to number of registrations in the ACR (see table 4) or according to number of registers in which a person was found (see table 6) were compared with the same numbers in the categories without registrations the. $R \mathbf{R}$ was computed as an odds ratio. The $95 \%$ CI was calculated according to the test based method. ${ }^{23}$

Expected numbers of deaths for the painters were calculated by applying the person-years distribution of the painters within five year age categories to all men in Stockholm county. The calculations were performed for each calendar year and the fractional contributions were summarised for all age groups and calendar years.

\section{Results}

The results section examines the incidence of alcoholism and neuropsychiatric disorders, as well as the occurrence of alcohol abuse in the different registers among painters compared with carpenters. The risk of being found in multiple registers due to indications of alcohol abuse was also compared between the two groups. 
Table 2 First diagnoses at early retirement among painters compared with carpenters during the period 1971-84

\begin{tabular}{llcl}
\hline$I C D-8$ & Diagnosis & Obs & $R R(95 \% C I)$ \\
\hline $1-999$ & All diagnoses & 46 & $1 \cdot 3(0 \cdot 9-1 \cdot 9)$ \\
$290-315$ & Psychiatric disturbances & 15 & $6 \cdot 5(2 \cdot 5-17)$ \\
303 & Alcoholism & 9 & $8 \cdot 0(2 \cdot 2-29)$ \\
& RDEA & 4 & $3.5(0 \cdot 7-16)$ \\
$390-458$ & Circulatory diseases & 1 & $0 \cdot 1(0 \cdot 0-0 \cdot 8)$ \\
$710-738$ & Musculoskeletal diseases & 10 & $0 \cdot 9(0 \cdot 4-1.9)$ \\
\hline
\end{tabular}

^Relevant diagnoses except alcoholism (see Material and methods for explanation).

Calculations of risk started 1 January 1971 and ended at the date of early retirement, death, or 31 December 1984, whichever occurred first.

Obs $=$ No seen

REGISTER OF DIAGNOSES AT EARLY RETIREMENT (RDER) The painters received diagnoses of psychiatric illness more often and diagnoses of circulatory disorders less often than the carpenters (table 2). Alcoholism was the most common psychiatric disorder among the painters, with a high RR $(8 \cdot 0,95 \%$ CI $2 \cdot 2-29)$. Only one painter had a chronic toxic encephalopathy due to exposure to organic solvents as his primary diagnosis, and two painters had this diagnosis as an ancillary diagnosis.

\section{REGISTER OF DIAGNOSES AT DISCHARGE FROM INPATIENT PSYCHIATRIC CARE (RDP)}

There was an excess of diagnoses of all psychiatric disorders, including psychosis and the relevant diagnoses linked to the solvent syndrome among the painters (table 3). The main psychiatric disorder diagnosed was alcoholism.

Among those who had been admitted to hospital due to a diagnosis of alcohol psychosis or alcoholism there was no trend towards an increased number of admissions among painters compared with carpenters.

\section{ALCOHOL CRIME REGISTER (ACR)}

No excess risk existed for painters to be in this register. The RR for being found at least once was 1.1. Painters who were found once, however, were more likely than the carpenters to be found in the register several times (table 4 ).

Table 3 Diagnoses at first discharge from inpatient psychiatric care among painters compared with carpenters during the period 1968-83

\begin{tabular}{clcl}
\hline$I C D-8$ & Diagnosis & Obs & $R R(95 \% C I)$ \\
\hline $1-999$ & All diagnoses & 45 & $1 \cdot 5(1 \cdot 0-2 \cdot 3)$ \\
& RDEA ${ }^{\star}$ & 10 & $1 \cdot 3(0 \cdot 6-3 \cdot 0)$ \\
291,303 & Alcohol psychosis, alcoholism & 26 & $1 \cdot 9(1 \cdot 1-3 \cdot 4)$ \\
$292-295$ & Other psychoses & 6 & $2 \cdot 4(0 \cdot 7-8 \cdot 4)$ \\
\hline
\end{tabular}

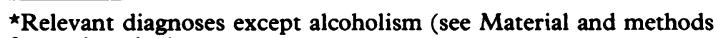
for explanation).

Calculations of risk started 1 January 1968 or 10 years after the entry into the union, whichever occurred latest, and ended with the first discharge from inpatient psychiatric care, death, or 31 December 1983, whichever occurred first.
REGISTER OF CAUSES OF DEATH (RCD)

The total mortality was similar in the two cohorts but the mortality pattern was different (table 5). Diagnoses of alcoholism, cirrhosis of the liver, and violent causes of death were more common among the painters than the carpenters. Alcohol was also mentioned on the death certificates as a contributing cause of death more often among the painters; however, all 95\% CIs encompassed unity.

Compared with expected numbers generated from the male population in Stockholm county the results suggest that the painters had some excess of alcoholism but not of violent deaths or liver cirrhosis.

\section{REGISTRATION DUE TO ALCOHOL ABUSE IN SEVERAL} REGISTERS

Registration of a person in several registers due to indications of or the result of alcohol abuse suggests more severe alcohol damage than registration in one register only. Table 6 shows the distribution of painters and carpenters according to the number of registers in which they were found due to any of the mentioned diagnoses or indications of alcohol abuse.

The number of persons registered in one register only was not increased among the painters although painters had an excess risk of being registered in several registers. The RR of being found in two or more registers was $2 \cdot 0(95 \%$ CI $1 \cdot 1-3 \cdot 5)$. The total numbers of painters and carpenters who were registered in at least two registers, or at least twice in the ACR, or both were 36 and 34 respectively $(R R=1 \cdot 7$, $95 \%$ CI $1 \cdot 1-2 \cdot 7$ ).

\section{Discussion}

The results indicate an excess risk for painters to have a more severe social impact from alcohol abuse than carpenters. Possible interpretations of this result are discussed after considering the relation beween diagnosis of alcohol abuse in the different registers and true alcohol abuse, the relation between painting and other neuropsychiatric diagnoses, and the comparability of the two cohorts.

Table 4 No of cohort members who were not registered in the alcohol crime register during the period 1972-6 and the number of cohort members with 1, 2-4, and 5 or more registrations during life up to and including 1976 among those with at least one registration during 1972-6

\begin{tabular}{lccll}
\hline \multirow{5}{*}{ Go of registrations } \\
\cline { 2 - 5 } & 0 & 1 & $2-4$ & $\geqslant 5$ \\
\hline Painters & 733 & 10 & 11 & 13 \\
Carpenters & 1161 & 25 & 14 & 12 \\
RR & $1.0^{\star}$ & 0.6 & $1 \cdot 2$ & $1 \cdot 7$ \\
$95 \%$ CI & & $0.3-1 \cdot 3$ & $0.6-2 \cdot 8$ & $0.8-3 \cdot 8$ \\
\hline
\end{tabular}

^Reference category. 
Table 5 Causes of death among the painters compared with the carpenters during the period 1965-86 (RR)

\begin{tabular}{|c|c|c|c|c|}
\hline$I C D-8$ & Diagnosis & Obs & $R R(95 \% C I)$ & $\operatorname{Exp}\left(S_{m p}\right)$ \\
\hline $\begin{array}{r}1-999 \\
140-209 \\
303\end{array}$ & $\begin{array}{l}\text { All } \\
\text { Cancer } \\
\text { Alcoholism } \\
\text { Alcohol, death } \\
\text { certificate` }\end{array}$ & $\begin{array}{r}40 \\
4 \\
6 \\
7\end{array}$ & $\begin{array}{l}1 \cdot 1(0 \cdot 7-1 \cdot 6) \\
0.4(0 \cdot 1-1 \cdot 1) \\
2.0(0.6-6.5) \\
1.4(0.5-3.9)\end{array}$ & $\begin{array}{r}52 \cdot 1 \\
9 \cdot 6 \\
2 \cdot 9\end{array}$ \\
\hline $390-458$ & $\begin{array}{c}\text { Circulatory } \\
\text { diseases }\end{array}$ & 7 & $0.7(0.3-1.6)$ & $13 \cdot 0$ \\
\hline $\begin{array}{r}571 \\
800-999\end{array}$ & $\begin{array}{l}\text { Liver cirrhosis } \\
\text { Violent causes }\end{array}$ & $\begin{array}{r}3 \\
15\end{array}$ & $\begin{array}{l}1.3(0.3-5.4) \\
1.8(0.9-3.8)\end{array}$ & $\begin{array}{r}3 \cdot 4 \\
15 \cdot 7\end{array}$ \\
\hline
\end{tabular}

*Alcohol mentioned on death certificate but not as primary cause of death.

Risk calculations were based on the person-years found in table 1 . An expected number of deaths generated from the Stockholm male population (Smp) was also calculated.

RELATIONS BETWEEN DIAGNOSES OF ALCOHOL USE IN THE DIFFERENT REGISTERS AND TRUE ALCOHOL ABUSE Diagnoses of alcohol abuse were more common among the painters than the carpenters in all registers studied. The painters, however, did not show an excess risk for just one registration in the ACR or for registration due to diagnosis of alcohol use in just one register and these two tendencies were independent of each other.

We are not aware of any studies on the relations between diagnoses of alcohol abuse in the different registers and true alcohol abuse; however, a registration in the ACR usually means that the subject has been arrested once for appearing drunk in public. It seems reasonable that this does not necessarily represent chronic alcohol abuse. Similarly, a registration in only one register suggests a less severe abuse than registrations in several registers. It is also likely that diagnoses of alcohol abuse in the PDR, or several registrations in the $A C R$, reflect a factual alcohol abuse. Diagnoses of alcohol abuse in the PDR usually indicate a need for acute treatment due to excess consumption during an extended period. Accordingly the results suggest that severe, but not slight, alcohol damage is more common among the painters than the carpenters.

Table 6 Indications of alcohol abuse among the painters and carpenters

\begin{tabular}{lcccl}
\hline \multirow{5}{*}{ Group } & \multicolumn{5}{l}{ Alcohol diagnosis in No of registers } \\
\cline { 2 - 5 } & 0 & 1 & 2 & $3-4$ \\
\hline Painters & 710 & 32 & 19 & 6 \\
Carpenters & 1138 & 54 & 17 & 3 \\
RR & $1.0^{\star}$ & 0.9 & 1.8 & 3.2 \\
$95 \%$ CI & & $0.6-1.5$ & $0.9-3.4$ & $0.9-12$ \\
\hline
\end{tabular}

$\star$ Reference category.

Indications were alcohol diagnosis (ICD-8 291,303) as main or ancillary diagnosis at any registration in the register of diagnoses at early retirement, or in the register of diagnoses at discharge from inpatient psychiatric care, or alcohol mentioned on the death certificate, or registration in the alcohol crime register.
RELATIONS BETWEEN THE OCCUPATION AS A PAINTER AND OTHER NEUROPSYCHIATRIC DIAGNOSES

Other neuropsychiatric diagnoses were also more common among the painters than among the carpenters but the RRs were smaller than for the diagnoses of alcohol abuse with $95 \%$ CIs constantly including unity, and the quantitative contribution to the class of neuropsychiatric diagnoses was also smaller. The cohorts were young, however, and the oldest cohort members had recently reached 60 years of age at the end of the follow up periods. The distribution of diagnoses of alcohol abuse and other diagnoses of other neuropsychiatric disorders may change as the cohorts age.

It is likely that a true excess of alcoholism would also be reflected in an excess of diagnoses of other neuropsychiatric disorders. Other diagnoses may in fact be preferred by the doctor as well as the patient to avoid the negative social consequences of diagnosis of alcoholism. On the other hand a diagnosis of alcoholism may in some cases have a rather pure solvent aetiology. It is impossible to determine the relative influence of these contradictory tendencies but they do not affect the basic finding of an excess of diagnoses of alcoholism among the painters.

Symptoms and clinical findings associated with a chronic toxic encephalopathy due to exposure to solvents may be diagnosed differently from those included in the combination of "relevant diagnoses". We investigated several combinations of diagnoses but the overall results did not change.

Ancillary diagnoses were noted in the RDER as well as the PDR. The distribution of neuropsychiatric disorders between painters and carpenters was not changed when ancillary diagnoses were included in the analyses.

\section{COMPARABILITY OF THE COHORTS}

The carpenters were chosen as the comparison group in this study because they have an occupation that is similar to the painters in many respects, although they, in general, have had an insignificant solvent exposure.

The general comparability of the painters and the carpenters is supported by the results in the psychometric tests that were performed at compulsory military conscription. We have collected results from these tests for about $80 \%$ of the cohorts. The results for the two groups were similar over the entire period followed-namely, 1944-63 (Almqvist $O$ et al, unpublished observations). These tests, however, measured only cognitive functions and were not personality tests.

Nevertheless it should be considered whether the excess risk of alcohol diagnoses among the painters may reflect the fact that the carpenters had a particularly low risk of alcoholism. The variation in diagnoses of alcoholism between different occupa- 
tions seems to be comparatively unknown ${ }^{24}$; published studies and statistics do not answer the question.

We could make some comparisons with the general population in the death register. The mortalities due to violent causes and cirrhosis of the liver showed a tendency to be increased among the painters in comparison with the carpenters but were close to the anticipated values in comparison with Stockholm county men. The painters had a tendency, however, to die more often from alcoholism than did the general population. These findings give some support to the view that alcoholism is more common among painters than in allied trades.

\section{INTERPRETATION OF THE RESULTS}

The interview, as well as the serum GGT activity determinations, showed that the current alcohol consumption was probably similar in the samples of painters and carpenters. The interview also suggested that the average consumption previously was not higher among the painters. Thus it is unlikely that a clearly different average alcohol consumption in the two cohorts could explain our finding of excess alcohol registrations among the painters. Even if the alcohol consumption had been different it could not immediately have explained the transition towards a more severe alcohol abuse that is present among the painters. There are several possible explanations for this finding:

(1) a high alcohol consumption has a tendency to become more excessive among painters than among carpenters.

(2) The damage produced by a high consumption of alcohol is more serious among painters than among carpenters.

(3) Painters who abuse alcohol may be able to stay in the occupation for more than 10 years (one of the inclusion criteria) whereas carpenters cannot.

Our data cannot exclude any of these explanations but the last explanation seems less likely as the RR for alcoholism was also increased among Swedish painters with less than 10 years in the trade as compared with the Swedish population. ${ }^{19}$

The other two explanations suggest that alcohol consumption may interact with another factor present among the painters to increase the severity of the abuse or the damage. The interviews that we performed with representative samples from the cohorts showed a high median cumulative exposure to solvents among the painters. The solvents have effects similar to alcohol on the central nervous system and may act synergistically.

Two mechanisms for the possible interaction between solvents and alcohol seem likely. The exposure to solvents may lead to increased consumption of alcohol through a desire to prolong the solvent effects on the central nervous system, similar to addiction.
Alcohol consumption has, in fact, been shown to correlate with exposure to toluene among printers. ${ }^{25}$ Furthermore, rats that were exposed to toluene and had access to alcohol as the only fluid preferred alcohol to water after toluene exposure to a much greater extent than rats that had had access to alcohol without simultaneous exposure to toluene. ${ }^{26}$ There could also be an interaction on the effect level so that the exposure to solvent and the consumption of alcohol interact to increase the damage on the central nervous system. It has been shown that exposure to solvent and consumption of alcohol may act additively to decrease the performance in some psychometric tests..$^{27-29}$

\section{Conclusion}

All individual or groups of diagnoses of neuropsychiatric disorders investigated were more common among the painters than among the carpenters. Diagnoses of alcohol abuse constituted most of the neuropsychiatric diagnoses and showed the highest relative risks. The diagnoses of alcohol abuse were not likely to be simple misdiagnoses of symptoms elicited purely by solvents as the outcome was established through different registers.

The excess risk of alcoholism among the painters, as compared to the carpenters, was confined to the groups of 36 painters and 34 carpenters $(R R=1 \cdot 7)$ who had been registered due to alcoholism in at least two registers, or registered in the alcohol crime register at least twice, or both, and thus showed more severe problems due to alcohol.

The results suggest that some factor linked to the painters' occupation may interact with the alcohol consumed to increase the risk of more severe alcohol abuse and more severe alcohol damage. Occupational exposure to solvents seems to be the most likely interacting factor.

Thus the findings are consistent with occupational exposure to solvents as a cause of the excess risk of diagnoses of alcoholism previously found among painters in several investigations. If this hypothesis is correct, the fraction of more severe alcohol problems caused by solvents, among the 36 painters with such problems in our study, would be about $40 \%$, with around 14 extra cases in the total cohort of 767 painters.

We thank Ms Monica Söderholm for help with the collection of data and Dr Lars Alfredsson for advice on the statistical analysis. Thanks are also due to Drs Christer Hogstedt and Bengt Sjögren for critical reading of the manuscript.

The study was financially supported by the Swedish Work Environment Fund. 
1 Knabenhans P. Über psychische Symptome bei Vergiftungen mit modernen gewerblichen Lösungsmitteln. Zurich: Inaugural-Dissertation. Aus der Psychiatrischen Universitätsklinik Zürich, 1941.

2 Grandjean E, Münchinger R, Turrian V, Haas P, Knoepfel H$\mathrm{K}$, Rosenmund $\mathrm{H}$. Investigations into the effects of exposure to trichloroethylene in mechanical engineering. $\mathrm{Br} J$ Ind $\mathrm{Med}$ 1955;12:131-42.

3 Axelson O, Hane M, Hogstedt C. A case-referent study on neuropsychiatric disorders among workers exposed to solvents. Scand J Work Environ Health 1976;2:14-20.

4 Lindström K, Riihimäki H, Hänninen H. Occupational solvent exposure and neuropsychiatric disorders. Scand J Work Environ Health 1984;10:321-3.

5 Mikkelsen S. A cohort study of disability pension and death among painters with special regard to disabling presenile dementia as an occupational disease. Scand J Soc Med Suppl $1980 ; 16: 34-43$.

6 Olsen J, Sabroe S. A case-referent study of neuropsychiatric disorders among workers exposed to solvents in the Danish wood and furniture industry. Scand J Soc Med Suppl 1980; 16:44-9.

7 Riise T, Moen B. A nested case-control study of disability pension among seamen, with special reference to neuropsychiatric disorders and exposure to solvents. Neuroepidemiology 1990;9:88-94.

8 Brackbill R, Maizlish N, Fischbach T. Risk of neuropsychiatric disability among painters in the United States. Scand $J$ Work Environ Health 1990;16:182-8.

9 Guberan E, Usel M, Raymond L, Tissot R, Sweetnam PM. Disability, mortality, and incidence of cancer among Geneva painters and electricians: a historical prospective study. $\mathrm{Br} J$ Ind Med 1989;46:16-23.

10 van Vliet C, Swaen G, Volovics A, Tweehuysen M, Meijers J, de Boorder T, Sturmans F. Neuropsychiatric disorders among solvent-exposed workers. First results from a Dutch casecontrol study. Int Arch Occup Environ Health 1990;62:127-32.

11 van Vliet C, Swaen G, Volovics A, Slangen J, Meijers J, de Boorder T, Sturmans F. Exposure-outcome relationships between organic solvent exposure and neuropsychiatric disorders: results from a dutch case-control study. Am J Ind Med 1989;16:707-18.

12 Cherry N, Waldron HA. The prevalence of psychiatric morbidity in solvent workers in Britain. Int J Epidemiol 1984; 13:197-200.

13 Rasmussen $\mathrm{H}$, Olsen J, Lauritsen J. Risk of encephlopathia among retired solvent-exposed workers. A case-control study among males applying for nursing home accommodation or other types of social support facilities. J Occup Med 1985;27:561-6.

14 Cherry N, Labreche F, McDonald C. Dementia and solvent exposure at work. In: Hogstedt C, Reuterwall C (eds): Progress in occupational epidemiology. International congress Series 829.
Amsterdam: Excerpta Medica, 1988.

15 Shalat S, Seltzer B, Baker E. Occupational risk factors and Alzheimer's disease: a case-control study. J Occup Med 1988;30:934-6.

16 O'Flynn R, Monkman S, Waldron H. Organic solvents and presenile dementia: a case-referent study using death certificates. Br J Ind Med 1987;44:259-62.

17 Errebo-Knudsen EO, Olsen F. Organic solvents and presenile dementia (The painters syndrome). A critical review of the Danish literature. Sci Total Environ 1986;48:45-67.

18 Grasso $P$, Sharratt $M$, Davies DM, Irvine $D$. Neurophysiological and psychological disorders and occupational exposure to organic solvents. Food Chem Toxicol 1984;22: 819-52.

19 Engholm G, Englund A. Cancer incidence and mortality among Swedish painters. In: Englund A, Ringen K, Mehlman M (Eds). Advances in modern environmental toxicology. Vol II: Occupational health hazards of solvents. Princeton: Princeton Scientific Publishers Inc, 1982.

20 Bobjer O, Knave B. Work load and exposure to solvents and dust-hazard factors in house painting. In: International symposium on the control of air pollution in the working environment. Stockholm: The Work Environment Fund/ILO, 1977:37-61.

21 Rollason JG, Pincherle G, Robinson D. Serum gamma glutamyl transpeptidase in relation to alcohol consumption. Clin Chim Acta 1972;39:75-80.

22 Rothman K. Modern epidemiology. Boston: Little, Brown and Co, 1986 .

23 Miettinen $O$. Estimability and estimation in case-referent studies. Am J Epidemiol 1976;103:226-35.

24 Ågren G. Alcohol-related mortality in relation to social factors in the county of Stockholm and in the whole of Sweden. Stockholm: Academic dissertation, Karolinska institute, Stockholm, 1989.

25 Hänninen H, Antti-Poika M, Savolainen P. Psychological performance, toluene exposure, and alcohol consumption in rotogravure printers. Int Arch Occup Environ Health 1987;59:475-83.

26 Pryor G, Howd R, Uyeno E, Thurber A. Interactions between toluene and alcohol. Pharmacol Biochm Behav 1985;23: 401-10.

27 Cherry N, Johnston JD, Venables H, Waldron HA, Buck L, McKay CJ. The effects of toluene and alcohol on psychomotor performance. Ergonomics 1983;26:1081-7.

28 Iregren A, Âkerstedt T, Anshelm Olson B, Gamberale F. Experimental exposure to toluene in combination with ethanol intake. Psychophysiological functions. Scand J Work Environ Health 1986;12:128-36.

29 Savolainen K. Combined effects of xylene and alcohol on the central nervous system. Acta Pharmacologica et Toxicologica 1980;46:366-72.

Accepted 7 October 1991 